\title{
Development and Subunit Composition of Synaptic NMDA Receptors in the Amygdala: NR2B Synapses in the Adult Central Amygdala
}

\author{
Mikel Lopez de Armentia and Pankaj Sah \\ Division of Neuroscience, John Curtin School of Medical Research, Australian National University, Canberra ACT 2601, Australia
}

\begin{abstract}
NMDA receptors are well known to play an important role in synaptic development and plasticity. Functional NMDA receptors are heteromultimers thought to contain two NR1 subunits and two or three NR2 subunits. In central neurons, NMDA receptors at immature glutamatergic synapses contain NR2B subunits and are largely replaced by NR2A subunits with development. At mature synapses, NMDA receptors are thought to be multimers that contain either NR1/NR2A or NR1/NR2A/NR2B subunits, whereas receptors that contain only NR1/NR2B subunits are extrasynaptic. Here, we have studied the properties of NMDA receptors at glutamatergic synapses in the lateral and central amygdala. We find that NMDA receptor-mediated synaptic currents in the central amygdala in both immature and mature synapses have slow kinetics and are substantially blocked by the NR2B-selective antagonists (1S, 2S)-1-(4-hydroxyphenyl)-2-(4-hydroxy4-phenylpiperidino)-1-propano and ifenprodil, indicating that there is no developmental change in subunit composition. In contrast, at synapses on pyramidal neurons in the lateral amygdala, whereas NMDA EPSCs at immature synapses are slow and blocked by NR2Bselective antagonists, at mature synapses their kinetics are faster and markedly less sensitive to NR2B-selective antagonists, consistent with a change from NR2B to NR2A subunits. Using real-time PCR and Western blotting, we show that in adults the ratio of levels of NR2B to NR2A subunits is greater in the central amygdala than in the lateral amygdala. These results show that the subunit composition synaptic NMDA receptors in the lateral and central amygdala undergo distinct developmental changes.
\end{abstract}

Key words: fear; memory; emotion; LTP; NR2A; learning

\section{Introduction}

Glutamate, the major excitatory transmitter in the mammalian CNS, activates three classes of ionotropic receptors: AMPA, kainate, and NMDA receptors that can be separated on biophysical and pharmacological grounds (Dingledine et al., 1999). AMPA and kainate receptors are functional at negative membrane potentials and mediate synaptic transmission at resting membrane potentials. In contrast, NMDA receptors require glutamate, glycine, and membrane depolarization for their activation (McBain and Mayer, 1994). These receptors are largely inactive during synaptic transmission at resting membrane potentials but play an important role in synaptic plasticity, development, and processes involved in learning and memory (Cull-Candy et al., 2001).

NMDA receptors are heteromeric complexes assembled from NR1 and NR2 subunits. The NR1 subunit, the product of a single alternatively spliced gene (Nakanishi et al., 1992; Laurie and Seeburg, 1994), is ubiquitously expressed through the CNS and contains the glycine binding site (Kuryatov et al., 1994). The NR2 subunit contains the glutamate binding site and is found as four

Received March 17, 2003; revised May 6, 2003; accepted May 30, 2003.

M.L.d.A. is supported by a grant from the Secretaria de Estado de Educacion y Universidades (Spain). We thank Frank Menniti (Pfizer, Groton, CT) for the gift of (P-101,606. We thank Nadine McCarthy for help with Western blots and Dr. John Clements for comments on this manuscript.

Correspondence should be addressed to Dr. Pankaj Sah, Queensland Brain Institute, School of Biomedical Sciences, University of Queensland, St. Lucia QLD 4072, Australia. E-mail: pankaj.sah@uq.edu.au

Copyright $\odot 2003$ Society for Neuroscience $\quad 0270-6474 / 03 / 236876-08 \$ 15.00 / 0$ different isoforms encoded by different genes NR2A-NR2D (McBain and Mayer, 1994; Cull-Candy et al., 2001). The presence of different NR2 subunits confers on the NMDA receptor distinct pharmacological and kinetic properties (Kutsuwada et al., 1992; Dingledine et al., 1999; Yamakura and Shimoji, 1999). When activated by glutamate, receptors containing NR2A subunits have rapid offset kinetics, whereas receptors containing NR2B, NR2C, and NR2D subunits have slower kinetics with time constants of NR2B $<$ NR2C $<$ NR2D (Vicini et al., 1998). In central neurons, NR2A and NR2B subunits are the most abundant, and NMDA receptors are formed by heteromultimers of NR1, NR2A, and NR2B subunits with NR1/NR2A and NR1/NR2B combinations being most abundant whereas NR1/NR2A/NR2B combinations are also present (Sheng et al., 1994; Luo et al., 1997). NR2C subunit expression is largely restricted to cerebellar granule cells, and NR2D subunits have not been detected at synapses (CullCandy et al., 2001).

NR2 subunit expression is developmentally regulated such that at birth NR2B is the predominant subunit. NR2A subunit expression begins around day 3 , after which there is a gradual increase in the expression of NR2A subunits (Monyer et al., 1994; Sheng et al., 1994; Zhong et al., 1995). With maturation, the change in subunit composition results in EPSCs that have faster kinetics and are markedly less sensitive to NR2B-selective antagonists (Carmignoto and Vicini, 1992; Hestrin, 1992; Flint et al., 1997; Stocca and Vicini, 1998). This change in subunit expression 
is thought to contribute to the developmental changes in NMDA receptor-mediated plasticity at glutamatergic synapses (CullCandy et al., 2001; Philpot et al., 2001).

The amygdala, a complex of nuclei in the temporal lobe, has consistently been shown to have a key role in the acquisition and expression of fear conditioning (LeDoux, 2000; Maren, 2001). Sensory information reaches the amygdala via the lateral amygdala (LA), is processed locally, and is then transmitted to the central amygdala (CeA). Afferents from the CeA to the hypothalamus and brainstem are responsible for the behavioral responses that accompany fear conditioning (LeDoux, 2000; Maren, 2001). Sensory inputs to LA pyramidal neurons form dual component glutamatergic synapses (Mahanty and Sah, 1999; Weisskopf and LeDoux, 1999) that undergo long-term potentiation after fear conditioning (Quirk et al., 1995; McKernan and ShinnickGallagher, 1997). Infusion of the NMDA receptor antagonist APV into the basolateral amygdala blocks the acquisition of fear conditioning (Miserendino et al., 1990). It has been proposed that NMDA receptor-dependent synaptic plasticity in the LA underlies the cellular changes that mediate associative fear conditioning (LeDoux, 2000; Maren, 2001). A recent study has shown that administration of the NR2B-specific receptor antagonist ifenprodil also blocks the acquisition of fear conditioning, suggesting that activation of NR2B receptors is essential in the induction of synaptic plasticity in the LA (Rodrigues et al., 2001). However, the possible contribution of NR2B subunits to synaptic transmission in the amygdala are not known.

Here, we examine the composition of synaptic NMDA receptors in the LA and CeA. We show that synaptic NMDA receptors in the LA are largely NR1/NR2B multimers at birth, but with maturation the NR2B subunits are largely replaced by receptors containing NR2A subunits. In contrast, in the central nucleus, there is no developmental change, and these synapses retain NR1/ NR2B multimers into adulthood. Thus, whereas all synapses initially begin with NMDA receptors that contain NR2B subunits, they undergo different developmental changes, and the subunit combinations present at synapses in CeA and LA are different in the adult.

\section{Materials and Methods}

Wistar rats ( $\mathrm{P} 5-\mathrm{P} 80)$ were anesthetized with intraperitoneal pentobarbitone $(50 \mathrm{mg} / \mathrm{kg})$, and coronal slices $(400 \mu \mathrm{m})$ were prepared using standard methods (Mahanty and Sah, 1999). For electrophysiological experiments, slices were transferred to the recording chamber after a 1-hr recovery and superfused with oxygenated $\left(95 \% \mathrm{O}_{2}-5 \% \mathrm{CO}_{2}\right)$ physiological solution containing (in mM): $118 \mathrm{NaCl}, 2.5 \mathrm{KCl}, 25 \mathrm{NaHCO}_{3}, 1.2$ $\mathrm{NaH}_{2} \mathrm{PO}_{4}, 1.3 \mathrm{MgCl}_{2}, 2.5 \mathrm{CaCl}_{2}$, and 10 glucose at $33-35^{\circ} \mathrm{C}$. Picrotoxin $(100 \mu \mathrm{M})$ was included in the perfusing ringer to block inhibitory transmission. For Western blots and real-time PCR experiments, tissue from the lateral and central nucleus were dissected from the slices under a stereomicroscope.

Whole-cell recordings were made from neurons of the lateral sector of the central amygdala $(\mathrm{CeL})$ and LA using the blind approach. Electrodes were filled with intracellular solution containing (mM): CsGluconate, 117.5; $\mathrm{CsCl}$, 17.5; $\mathrm{NaCl}, 8$; HEPES, 10 ; $\mathrm{Mg}_{2}$ ATP, $2 ; \mathrm{Na}_{3} \mathrm{GTP}$, 0.2; BAPTA, 10; and spermine, $0.1, \mathrm{pH} 7.3$ (osmolarity, $295 \mathrm{mOsm} / \mathrm{kg}$ ). This solution had a junction potential of $+13 \mathrm{mV}$, and all records have been corrected for this. Access resistance was 7-20 M $\Omega$ and was monitored throughout the experiment. Data were discarded if access resistance changed by $>10 \%$ during an experiment. Signals were recorded using an Axopatch 1-D (Axon Instruments, Foster City, CA), filtered at $5 \mathrm{kHz}$, and digitized at $10 \mathrm{kHz}$ (ITC 16; Instrutech, Port Washington, NY). Data were acquired and analyzed using Axograph 4.6 (Axon Instruments). All traces shown are averages of $10-15$ sweeps.

For recordings in the central nucleus, bipolar stainless steel electrodes
(FHC Inc., Bowdoinham, ME) were placed in the basolateral complex, and a separate stimulating electrode was placed on afferents entering the nucleus dorsomedially. Because no differences were found between these inputs, the data between them have been pooled. For recordings in the LA, stimulating electrodes were placed in the external capsule to activate cortical afferents and dorsomedially to the central nucleus to activate thalamic afferents (Mahanty and Sah, 1999; Weisskopf and LeDoux, 1999). For hippocampal recordings, pyramidal neurons were recorded from area CA1, and a stimulating electrode was placed in the stratum radiatum to activate Schaffer collaterals. Stimuli (50 $\mu$ s; $10-30 \mathrm{~V})$ were applied by constant-voltage-isolated stimulators (DS2A; Digitimer, Welwyn Garden City, UK). For comparison of deactivation kinetics of the NMDA receptor EPSCs, 15 evoked EPSCs were recorded at $+30 \mathrm{mV}$, averaged, and the current decays were fitted to a double exponential equation of the form:

$\mathrm{I}(\mathrm{t})=\mathrm{I}_{\mathrm{f}} \exp \left(-\mathrm{t} / \tau_{\mathrm{f}}\right)+\mathrm{I}_{\mathrm{s}} \exp \left(-\mathrm{t} / \tau_{\mathrm{s}}\right)$ where $\mathrm{I}_{\mathrm{f}}$ and $\mathrm{I}_{\mathrm{s}}$ are the amplitudes of the fast and slow and decay components, and $\tau_{\mathrm{f}}$ and $\tau_{\mathrm{s}}$ are their respective decay time constants. The weighted time constant was calculated as:

$$
\tau_{W}=\left[I_{f} d\left(I_{f}+I_{s}\right)\right] \tau_{f}+\left[I_{s} /\left(I_{f}+I_{s}\right)\right] \tau_{s}
$$

and was used for statistical comparisons of the decay times of the EPSCs. For experiments testing MK- 801 block, cells were held at $+30 \mathrm{mV}$ in the presence of $15 \mu \mathrm{M}$ CNQX, and synaptic inputs were activated every 10 sec. After a baseline of $5 \mathrm{~min}, 5 \mu \mathrm{M}$ MK- 801 was added to the bath, and synaptic stimulation was stopped to ensure that the drug concentration equilibrated. After $3 \mathrm{~min}$, synaptic inputs were activated every $10 \mathrm{sec}$ until MK-801 completely blocked the synaptic current. The progressive block by MK-801 was fit to a single exponential.

Semiquantitative real time PCR. Total RNA was prepared using Trizol (Invitrogen, San Diego, CA) and reverse transcribed using a RT-PCR kit (Invitrogen). cDNA expression was quantified using the Rotor-Gen 2000 system (Corbett Research, Mortlake, Australia) and Quantitec SYBRGreen PCR kit (Qiagen, Hilden, Germany). Primers used were as follows: NR2A (CAATCTGACTGGATCACAGAGC), (CTGTCCTTCCCTTGAAAGGATC); NR2B(GCCGGCAGCATTCCTACGACAC), (CCGGGGTTGTTGTGGTGGTGTC). No other products were amplified because melting curves showed only one peak in each sample. Fluorescence signals were measured over 50 PCR cycles. The cycle number $\left(\mathrm{C}_{\mathrm{t}}\right)$ at which the signals crossed a threshold set within the logarithmic phase was recorded. For quantitation, we evaluated $\Delta C_{t}$ as the difference in cycle threshold between NR2A and NR2B subunits. A $\Delta C_{t}$ of -1 indicates a twofold larger expression of NR2A subunits as compared with NR2B subunits (Rose-Meyer et al., 2003). The efficiency of amplification of both primers was tested by serial dilutions of the RNA for both subunits and plotting $\Delta \mathrm{C}_{\mathrm{t}}$ against $\log$ (total RNA). The slope of this line was linear (slope $=0.0371 ; r^{2}=0.956$ ), showing that the efficiencies of the two sets of primers were similar.

Western blot. Tissue from the LA and CeA was homogenized in a lysis buffer containing 5\% SDS, 0.01\% Bromophenol Blue, 8 m Urea, $0.1 \mathrm{~mm}$ EDTA, and $40 \mathrm{~mm}$ Tris, $\mathrm{pH}$ 6.8. Proteins were separated by SDS-PAGE (4-12\% gradient gel; Invitrogen) and electrophoretically transferred to an Immobilon-P membrane (Millipore, Bedford, MA). Blots were incubated with primary antibody (1:1000 rabbit polyclonal antibodies antiNR2A and anti-NR2B; Chemicon, Temecula, CA) overnight at $4^{\circ} \mathrm{C}$. Secondary antibody (1:1000 anti-rabbit horseradish peroxidase) was applied for $1 \mathrm{hr}$. Immunoreactive bands were visualized with chemiluminescence using an ECL kit (Amersham Biosciences, Sydney, Australia). Film autoradiograms were analyzed and quantified using National Institutes of Health image 1.6. Western blots were done independently from four animals using CeA and LA tissue from three slices in each animal.

Drugs used were CNQX, D-APV (Tocris Cookson, Bristol, UK), ifenprodil, MK-801, and picrotoxin (Sigma-Aldrich). All values are expressed as mean \pm SEM, and statistical comparisons were done using two-tailed $t$ tests or ANOVA, with significance set at $p<0.05$.

\section{Results}

Whole-cell recordings were made from neurons in the LA and in the central nucleus in coronal slices of rat brain slices. Recordings 
in the central nucleus were made from the lateral subdivision (CeL) (Cassell et al., 1986). In CeL neurons, at a holding potential of $-70 \mathrm{mV}$, stimulation of afferents evoked a rapidly rising and decaying synaptic current. Depolarization of the postsynaptic cell revealed a slowly decaying component of the inward current (Fig. $1 A)$. The current-voltage relationship $(I-V)$ of the fast component was linear with a reversal potential near $0 \mathrm{mV}$, typical for AMPA receptor-mediated currents, whereas the $I-V$ of the slower component showed a region of negative slope resistance (Fig. $1 B$ ), typical for currents mediated by NMDA receptors (Hestrin et al., 1990). The fast component was selectively blocked by AMPA/kainate receptor antagonist CNQX, whereas the slower component was blocked by the NMDA receptor antagonist D-APV (Fig. 1C). Thus, excitatory inputs to neurons in the CeL activate typical dual component glutamatergic synapses.

In recordings from animals aged $\mathrm{P} 21-$ P30, the AMPA receptor-mediated EPSC in CeL neurons had a $10-90 \%$ rise time of $1.8 \pm 0.4 \mathrm{msec}$ and decayed exponentially with a time constant of $4.4 \pm 0.3 \mathrm{msec}(n=20)$. The NMDA receptor component of the EPSC had a $10-90 \%$ rise time of $5.0 \pm 0.1 \mathrm{msec}(n=27)$. The decay of the EPSC (measured at $+30 \mathrm{mV}$ ) was best fit by two exponentials with time constants, $\tau_{\text {fast }}=95 \pm 14 \mathrm{msec}$ and $\tau_{\text {slow }}$ $=253 \pm 29 \mathrm{msec}$, with the amplitude of the fast component being $42 \pm 3 \%(n=31)$. The average weighted time constant was $162 \pm 9 \mathrm{msec}(n=30)$. Excitatory inputs to pyramidal neurons in the LA also activate dual component glutamatergic synapses (Mahanty and Sah, 1999; Weisskopf and LeDoux, 1999). The $10-90 \%$ rise time of the NMDA receptor current in LA neurons was $5.1 \pm 0.2 \mathrm{msec}(n=39)$, and the decay was best fit with two exponentials with a $\tau_{\text {fast }}=35 \pm 3 \mathrm{msec}$ and $\tau_{\text {slow }}=190 \pm 11$ msec, the amplitude of the fast component being $65 \pm 2 \%(n=$ 34 ). The weighted time constant for inputs to LA pyramidal neurons was similar for both cortical ( $84 \pm 4$ msec; $n=34)$ and thalamic ( $86 \pm 6 \mathrm{msec} ; n=19)$ inputs. These values are significantly faster $(p<0.001)$ than those obtained in CeL neurons (Fig. 1D), suggesting a different synaptic NMDA receptor subunit composition between the two nuclei of the amygdala.

The slower kinetics of the NMDA receptor-mediated synaptic current in adult CeL neurons suggests that these receptors preferentially contain NR2B subunits (Flint et al., 1997; Vicini et al., 1998; Tovar and Westbrook, 1999). We next tested the effects of the selective NR2B antagonists (1S, 2S)-1-(4-hydroxyphenyl)2-(4-hydroxy-4-phenylpiperidino)-1-propanol (CP-101,606) and ifenprodil (Williams, 1993; Chenard and Menniti, 1999) on NMDA receptor-mediated synaptic currents in CeL and LA neurons. In CeL neurons, application of CP-101,606 (5 $\mu \mathrm{M})$ reduced the amplitude of the evoked EPSC by $68 \pm 5 \%(n=9)$; similar results were seen with ifenprodil $(10 \mu \mathrm{M} ; 64 \pm 7 \% ; n=6)$. This reduction in the amplitude of the EPSC is similar to that seen with expressed NMDA receptors containing NR1/NR2B subunits (Vicini et al., 1998; Tovar and Westbrook, 1999), indicating that NMDA receptors at synapses on CeL neurons contain NR2B subunits. The kinetics of the EPSC in the presence of the NR2B
B
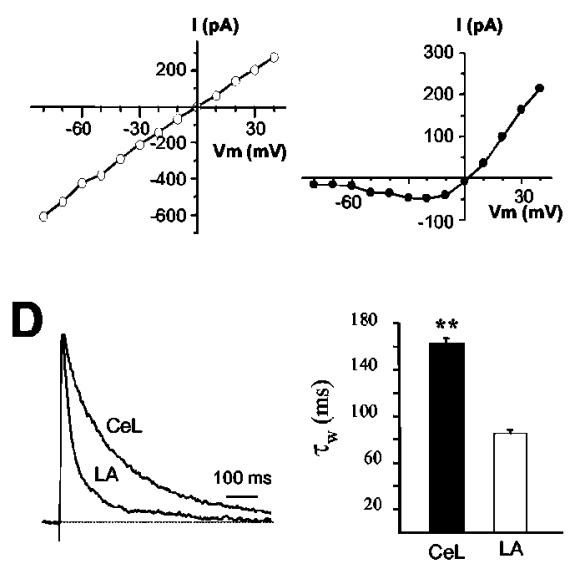

Figure 1. NMDA receptor-mediated synaptic currents in the central nucleus have slow kinetics. $A$, Whole-cell recording from a fast component was abolished by the AMPA/kainate antagonist CNQX (15 $\mu \mathrm{M})$. The slow current present at deploarized potentials was blocked by the NMDA receptor antagonist D-APV $(30 \mu \mathrm{M})$. D, Normalized NMDA receptor-mediated EPSCs recorded at +30 decay is much faster in LA neurons. The histogram shows the average weighted decay time constants (see "Materials and Methods") of the NMDA receptor-mediated EPSC in (eL and LA neurons. All recordings were from animals P21-P30.

blockers was not different from that recorded in control conditions (Fig. $2 \mathrm{~A}_{2}$ ), consistent with the presence of a single population of NR1/NR2B-containing receptors at these synapses. In contrast, at inputs to pyramidal neurons in the LA, application of CP-101,606 or ifenprodil reduced the evoked EPSC by $34 \pm 4 \%$ $(n=9$; Fig. $2 B)$ and $36 \pm 19 \%(n=3)$, respectively. Unlike CeL neurons, there was a clear reduction in the slow component of the EPSC in the presence of CP-101,606 (Fig. 2 B) or ifenprodil. The contribution of the fast component of the EPSC increased from $62 \pm 3 \%$ to $73 \pm 6 \%$ in the presence of CP-101,606. These effects were not because of a reduction in transmitter release, because neither CP-101,606 (Fig. 2B, inset) nor ifenprodil (data not shown) had any effects on AMPA receptor-mediated EPSCs.

Together, these results indicate that NMDA receptors at synapses on CeL neurons contain largely NR2B subunits, whereas the contribution of NR2B subunits to NMDA receptor synapses in the LA is much lower (Flint et al., 1997; Vicini et al., 1998; Tovar and Westbrook, 1999). To confirm this finding, we tested for differences in the expression levels of NR2A and NR2B subunits between the two nuclei. We first tested for differences in mRNA levels for the two subunits using semiquantitative realtime PCR. The difference in cycle threshold between NR2A and NR2B subunits ( $\Delta \mathrm{C}_{\mathrm{t}}$; see "Materials and Methods") for the central nucleus was $1.1 \pm 1.7$ as compared with $-3.4 \pm 0.8(n=3)$ for the LA (Fig. $3 B$ ), indicating that expression of NR2B mRNA is more abundant than NR2A mRNA in the central nucleus, whereas NR2A mRNA is more abundant in the lateral nucleus. Consistent with the PCR results, Western blots also showed that NR2B protein level is significantly higher than NR2A levels in the CeA as compared with the LA (Fig. 3C).

These results show that at glutamatergic synapses on CeL neurons, NMDA receptors have a subunit composition similar to that seen at immature synapses, whereas at synapses in the LA, NMDA receptors have a more mature phenotype. We next tested whether synaptic NMDA receptors in the LA undergo a developmental change in subunit composition, as has been described in 
$\mathbf{A}_{1}$

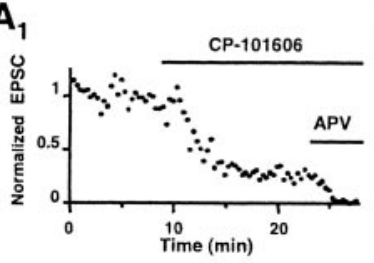

$\mathbf{B}_{1}$

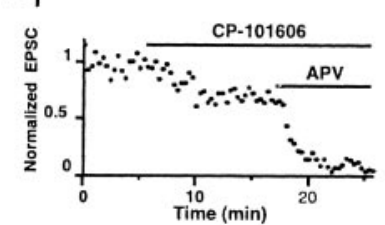

$\mathrm{B}_{2}$

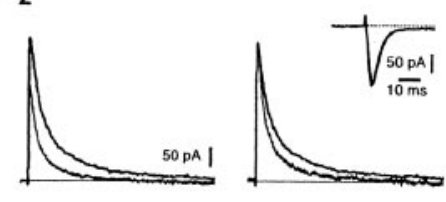

$A_{2}$

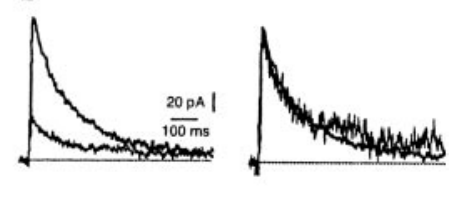

Figure 2. NMDA receptors at synapses in CeA neurons contain NR2B subunits. $A_{1}$, Normalized amplitude of NMDA EPSCS recorded from a neuron in the CeA in the presence of CNQX and picrotoxin. Application of the NR2B-specific antagonist (P-101,606 $(5 \mu \mathrm{M})$ largely blocked the EPSC. The remaining EPSC in (P-101,606 is blocked by D-APV $(30 \mu \mathrm{M})$, showing that it is mediated by NMDA receptors. $A_{2}$, NMDA EPSC in control ringer and in the presence of (P-101,606 have been superimposed (left traces). When the EPSC in the presence of the NR2B antagonist is normalized to the control EPSC, there is no change in kinetics showing that it is also mediated by receptors containing NR2B subunits. $B$, Effect of CP-101,606 on the NMDA receptor-mediated EPSC in a pyramidal neuron in the LA. $B_{1}$, Normalized amplitude of NMDA EPSCs recorded from a neuron in the LA in the presence of CNQX and picrotoxin. Application of $5 \mu \mathrm{M}$ CP-101,606 partially blocks the EPSC, and the remaining EPSC is blocked by D-APV (30 $\mu \mathrm{M})$, confirming that it is mediated by NMDA receptors. $B_{2}$, EPSCs in control and CP-101,606 are shown superimposed. Normalizing the traces shows that the slow component of the EPSC is selectively blocked by CP-101,606 in LA neurons. The inset shows AMPA receptor-mediated EPSCs recorded at $-70 \mathrm{mV}$ from a neuron in the CeL before and after application of CP-101,606. CP-101,606 has no presynaptic effect on transmitter release at these synapses. All recordings were from animals P21-P30.

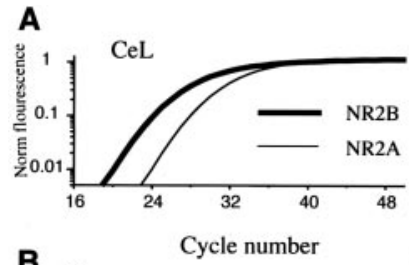

B

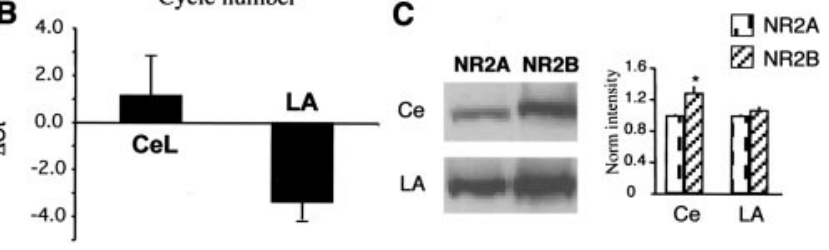

Figure 3. NR2B subunits are expressed at higher levels in the central nucleus as compared with the LA in animals P21-P30. A, Real-time PCR fluorescence is plotted against cycle number using primers against the NR2A subunit (thin line) and NR2B subunit (thick line). In the central amygdala (Ce), the fluorescence change for NR2B subunits occurs before that for NR2A subunits, whereas in the $L A$, fluorescence for $2 A$ subunits rises before that for NR2B subunits. $B$, Ratio of threshold cycle (Ct) between NR2A and NR2B subunits for the $C e$ and LA. In each case, tissue from the $C e$ and LA were run in parallel. C, Western blot of protein levels for NR2A and NR2B subunits in the Ce and LA. The bar graph on the right plots the intensity levels normalized to that for NR2A in the Ce and LA. NR2B levels are significantly higher than NR2A levels in the central nucleus.

other forebrain regions (Carmignoto and Vicini, 1992; Hestrin, 1992; Monyer et al., 1994; Flint et al., 1997). In recordings from LA neurons in P5 animals, the NMDA receptor-mediated EPSC was similar to that recorded from adult CeL neurons and had a weighted decay time constant of $151 \pm 16 \mathrm{msec}(n=8$; Fig. $4 A, B)$. Application of CP-101,606 (5 $\mu \mathrm{M})$ blocked the EPSC by $77 \pm 7 \%(n=3)$, showing that synaptic NMDA receptors in the LA in P5 animals contain NR2B subunits. In contrast, NMDA EPSCs recorded in P80 animals were similar to those recorded in neurons from 3- to 4-week-old animals (compare Fig. 1), had a weighted decay constant of $90 \pm 10 \operatorname{msec}(n=4)$, and CP-
101,606 blocked them by $39 \pm 15 \%(n=$ 3) (Fig. 4B). To check whether the slow decay of EPSCs in CeL neurons in P21 animals could be because of a delayed maturation of these synapses, NMDA receptormediated EPSCs in the central nucleus were also recorded from P80 animals. These EPSCs had a weighted decay time constant of $150 \pm 13 \mathrm{msec}(n=8)$, similar to that in P21 animals (Fig. 4C). Thus, NMDA receptors in CeL neurons do not change with maturation, whereas those in the LA pyramidal neurons do.

It has recently been shown that at developmentally immature synapses, where NMDA receptors contain NR1/NR2B subunits, transmitter release probability is high (Chavis and Westbrook, 2001). With development, as NR2B subunits are replaced by NR2A subunits, there is a concomitant reduction in release probability (Chavis and Westbrook, 2001). Because NMDA synapses in CeL neurons maintain their immature phenotype with regard to the subunit composition of synaptic NMDA receptors, we tested whether these synapses would also display a higher release probability as compared with inputs to LA neurons. One measure of the probability of glutamate release is the progressive block of synaptic NMDA currents by the irreversible NMDA open-channel blocker MK-801 (Huettner and Bean, 1988; Rosenmund et al., 1993). During repetitive stimulation in the presence of MK-801, synapses with high-release probability are blocked faster than those with lower-release probability (Rosenmund et al., 1993; Chavis and Westbrook, 2001). We tested the rate of progressive block of synaptic currents by MK-801 in LA and CeL neurons. In both the CeL and LA, the block of EPSCs by MK-801 was well fit with a single exponential, suggesting these inputs have a uniform population of release sites with similar release probabilities. The time constant of MK-801 block at synapses on CeL neurons was $23 \pm 3$ stimuli $(n=7)$. This is significantly faster $(p<0.05)$ than at inputs to LA neurons, in which the time constant was $48 \pm 7$ stimuli $(n=8$; Fig. $4 D$ ). This result is consistent with the release probability being significantly higher at inputs to the central nucleus as compared with inputs to neurons in the LA.

As described previously, the presence of synaptic NMDA receptors that predominantly have NR2B subunits results in NMDA receptor EPSCs with much slower kinetics. To test whether the slower decay kinetics impact on temporal summation of the NMDA component of EPSCs (Philpot et al., 2001), we compared the effects of repetitive stimulation at synapses in the LA and CeL neurons. As shown in Figure 5, repetitive activation of synapses in CeL neurons led to much larger summation of the NMDA EPSC compared with inputs to the LA.

These results show that, as in other parts of the forebrain, NMDA receptors at synapses on pyramidal neurons in the LA undergo a developmental change from those containing NR2B subunits to those containing largely NR2A subunits. Expressed NMDA receptors that contain NR1/NR2A subunits are not affected by NR2B antagonists (Williams et al., 1993; Vicini et al., 1998; Tovar and Westbrook, 1999). However, at synapses in the 
A

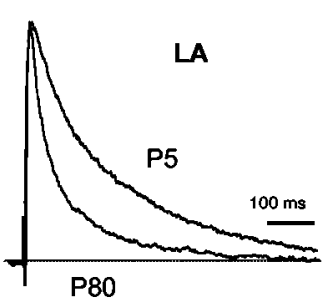

C

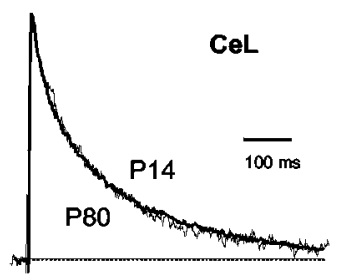

B

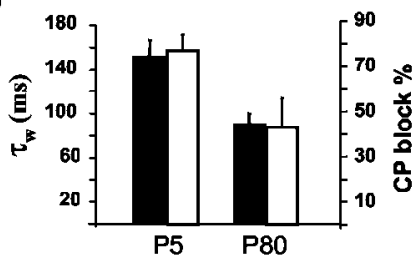

D

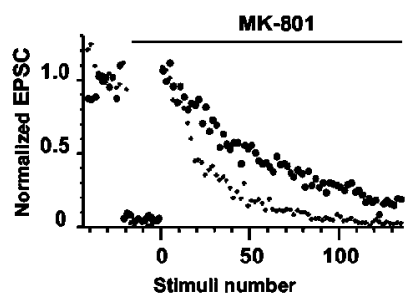

Figure 4. NMDA receptors undergo a developmental change in the $L A$ but not in the CeA. $A$, Normalized NMDA receptor-mediated EPSCs recorded from pyramidal neurons in the LA from animals at P5 and P80. B, Average weighted time constants (filled bars) and percentage block by (P-101,606 (open bars) for the two age groups in LA neurons. The slow decay of the EPSC in $L$ A neurons at $P 5$ is because of the presence of NR2B-containing subunits, as shown by the much larger block of the EPSC by CP-101,606. C, Normalized NMDA receptor-mediated EPSCs recorded from neurons in the CeL at P14 and P80. D, Release probability is higher at NR2B-containing synapses. Normalized amplitude of the NMDA receptor EPSC is plotted before and after application of $5 \mu \mathrm{M}$ MK-801. Progressive block of the NMDA EPSC by MK-801 is faster at synapses in the central nucleus (small circles) as compared with synapses in the LA (large circles).

LA, the NMDA receptor component is partially blocked by CP101,606 (Fig. 2). This result suggests that receptors containing NR2B subunits are present at mature synapses in the LA. In hippocampal pyramidal neurons, NMDA receptors at adult synapses are thought to contain largely NR2A subunits (Tovar and Westbrook, 1999). We, therefore, compared the properties of synapses at hippocampal pyramidal neurons with those in the LA. The kinetics of the NMDA receptor-mediated EPSC at Schaffer collateral synapses in area CA1 was similar to the kinetics in LA neurons (Fig. 6A). EPSCs recorded in CA1 pyramidal neurons had a weighted time constant of $84 \pm 4 \mathrm{msec}(n=10)$, similar to that in LA neurons (Fig. 6A). However, unlike in LA neurons, neither CP-101,606 (5 $\mu \mathrm{M} ; n=6)$ nor ifenprodil (10 $\mu \mathrm{M} ; n=7)$ had any effect on the NMDA EPSC in CA1 pyramidal neurons (Fig. 6B). This lack of effect of ifenprodil and CP-101,606 was not because of problems of access of these compounds in hippocampal slices, because application of these compounds to EPSCs in slices from P5 animals $(n=2$; Fig. $6 B)$ and the response to exogenously applied NMDA in adult slices $(n=2$; data not shown) showed a robust blockade by CP-101,606 of $80 \%$. Thus, as in visual cortical neurons (Stocca and Vicini, 1998) and cultured hippocampal neurons (Tovar and Westbrook, 1999), NMDA receptors at Schaffer collateral synapses in the adult hippocampus express NMDA receptors that are insensitive to NR2B-selective antagonists. Receptors containing NR1/NR2B subunits are present on mature neurons but are extrasynaptic.

\section{Discussion}

At most glutamatergic synapses, the abundant NR2B subunits present at birth are gradually replaced by NR2A subunits during development (Carmignoto and Vicini, 1992; Hestrin, 1992; Flint et al., 1997; Stocca and Vicini, 1998). Thus, at newly formed synapses, NMDA receptors largely consist of NR1/NR2B sub-

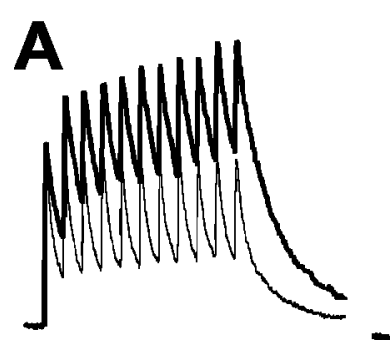

$10 \mathrm{~Hz}$

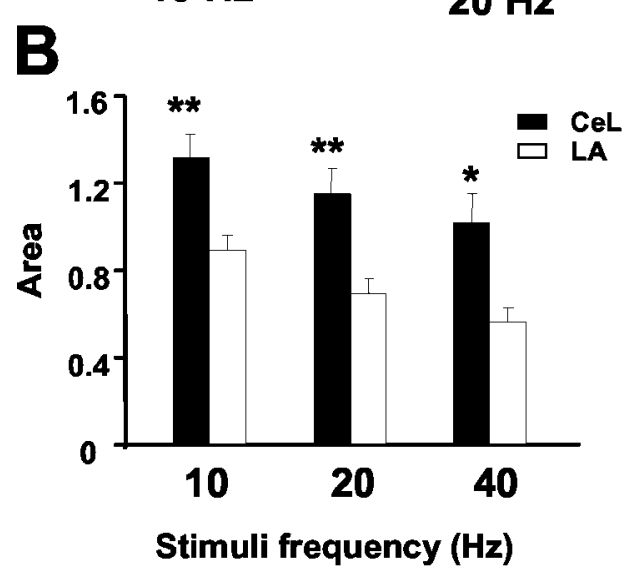

Figure 5. Temporal summation of NMDA receptor-mediated EPSCs is larger in the CeL neurons as compared with LA neurons. A, NMDA receptor-mediated EPSCs recorded at $+30 \mathrm{mV}$ during repetitive stimulation at 10,20 , and $40 \mathrm{~Hz}$. EPSCs recorded from CeL neurons (dark trace) and LA neurons (light traces) are superimposed. The first EPSC in the train has been normalized in each case. B, The area under the summed EPSCS, calculated after normalizing the first EPSC, has been plotted for inputs to neurons in CeL neurons $(n=6)$ and LA pyramidal neurons $(n=$ 8). All recordings were from animals P21-P30.

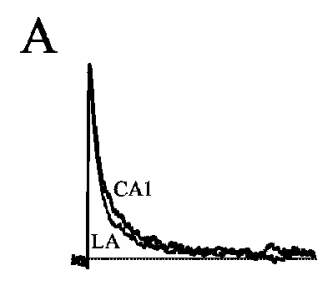

B

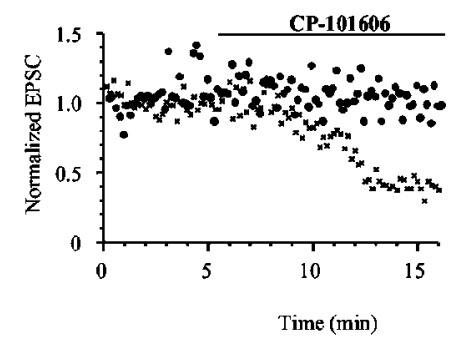

$\mathrm{C}$

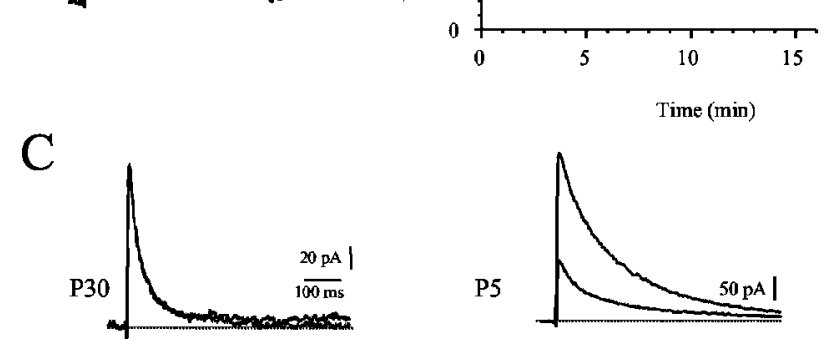

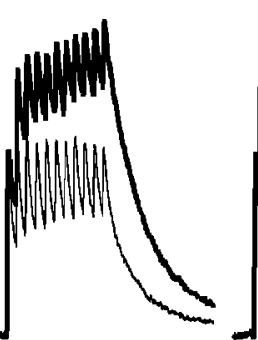

$40 \mathrm{~Hz}$

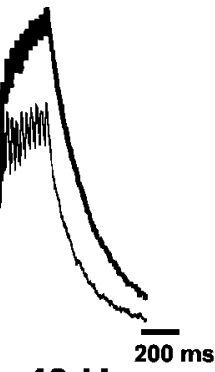

Figure 6. NMDA receptors at Schaffer collateral to CA1 pyramidal neuron synapses are kinetically similar to those in LA neurons, but are pharmacologically different. $A$, Normalized NMDA EPSCs recorded in slices from P21-P30 rats from CA1 pyramidal neurons and an EPSC recorded in LA neurons have been superimposed (left). Average weighted time constants for NMDA receptor EPSCs from the LA and CA1 pyramidal neurons, showing that kinetically they are very similar. $B, E P S C$ in hippocampal neurons from $P 5$ animals express higher levels of NR2B subunits. Block of the NMDA receptor-mediated EPSC by the NR2B-selective antagonist CP101,606 (5 $\mu \mathrm{M}$ ) at hippocampal CA1 synapses from animals at P5 (crosses) and at P30. NMDA EPSCs before and after application of (P-101,606 have been superimposed from P30 animals (top traces) and P5 animals (lower traces). (P-101,606 has no effect on EPSCS at mature synapses. 
units. At mature synapses, NR2A-containing receptors are targeted to synapses, whereas receptors containing only NR2B subunits are largely excluded from the postsynaptic membrane (Tovar and Westbrook, 1999). Consistent with this developmental profile, we have shown that in pyramidal neurons of the LA, developmentally immature synapses express NMDA receptors composed of NR1/NR2B subunits. With development, there is a switch to NR2A subunits, and receptors at adult synapses contain both NR2A and NR2B subunits. In contrast, at synapses on CeL neurons, there is no developmental change, and NR2Bcontaining receptors present at immature synapses are maintained into adulthood. This lack of change in the physiology of synaptic currents is consistent with the higher expression level of NR2B subunits in the central nucleus. Furthermore, the higherrelease probability seen at synapses in the CeL suggests that these synapses maintain their immature phenotype into adulthood (Chavis and Westbrook, 2001).

In agreement with the relative abundance of NR2B subunits early in development, coexpression of NR1 and NR2B subunits results in NMDA receptors that have kinetics and pharmacological properties similar with those of NMDA receptor EPSCs at immature synapses. As for the EPSCs, when activated by glutamate, NR1/NR2B-containing receptors have slow offset kinetics and are significantly blocked by NR2B-selective antagonists (Vicini et al., 1998; Tovar and Westbrook, 1999). The presence of NR2A subunits accelerates the offset kinetics and reduces their sensitivity to NR2B-selective antagonists (Vicini et al., 1998; Tovar and Westbrook, 1999). At inputs onto CeL neurons, because neither EPSC kinetics nor its sensitivity to NR2B-selective antagonists changes with development, it is clear that NR2A subunits make little contribution to NMDA receptors at these synapses. In contrast, at synapses on pyramidal neurons in the LA, NMDA EPSCs at immature synapses have properties consistent with those of receptors containing NR1/NR2B subunits. However, with development, these EPSCs have faster decay kinetics and a markedly reduced sensitivity to ifenprodil and CP-101,606, indicating that at mature synapses in LA neurons NMDA receptors contain NR2A subunits (Flint et al., 1997; Stocca and Vicini, 1998; Tovar and Westbrook, 1999).

For hippocampal synapses in culture, the developmental change in NMDA subunit composition is accompanied with a reduction in release probability (Chavis and Westbrook, 2001). Consistent with the presence of abundant NR2B subunits at synapses on CeL neurons, the release probability at these synapses seems to be higher than that at synapses in the LA. Release probability was assessed by progressive block by MK-801 of the NMDA EPSC (Huettner and Bean, 1988; Rosenmund et al., 1993). The rate of block of the NMDA EPSC by MK-801 depends on both the synaptic release probability and the open probability of the NMDA receptor (Rosenmund et al., 1993; Chen et al., 1999). As compared with receptors containing NR1/NR2B subunits, NR1/NR2A-containing receptors have been shown to have significantly higher peak open probability (Chen et al., 1999; for review, see Prybylowski et al., 2002). This result indicates that at terminals with similar release probabilities, the rate of MK-801 block at synapses containing NR2B subunits should be slower than at synapses that contain predominantly NR2A subunits. Thus, our finding of a faster block of the EPSC in CeL neurons (that contain NR2B subunits) is likely to have been underestimated and is consistent with these synapses maintaining a more immature phenotype (Chavis and Westbrook, 2001). It should be noted, however, that comparisons of channel open probability have only been done on expressed receptors containing either
NR2A or NR2B subunits. The open probability of receptors containing both subunits has not been determined. If the receptors present at synapses in the LA consist of heterotrimers (NR1/ NR2A/NR2B; see below), it remains possible that the slower block by MK-801 results from a difference in open probability.

At mature synapses in the LA, NMDA receptor EPSCs have kinetic properties similar to those at hippocampal synapses, consistent with the presence of NR2A subunits (Flint et al., 1997; Stocca and Vicini, 1998; Tovar and Westbrook, 1999). However, unlike in the hippocampus in which the NMDA EPSC is insensitive to NR2B-selective antagonists (Fig. 6), EPSCs in LA pyramidal neurons are partially blocked by NR2B-selective antagonists (Fig. 2). What, then, explains the finding that these EPSCs, kinetically similar to EPSCs in hippocampal neurons, are sensitive to NR2B-selective antagonists whereas those in the hippocampus are not?

At other central synapses, the developmental change from NR2B to NR2A subunits results in NMDA receptor EPSCs that have faster kinetics and are insensitive to NR2B antagonists (Stocca and Vicini, 1998; Rumbaugh and Vicini, 1999), consistent with the presence of NMDA receptors that contain, exclusively, NR1/NR2A heteromultimers (Williams et al., 1993; Vicini et al., 1998; Tovar and Westbrook, 1999). In agreement with this, we have shown that at synapses in the adult hippocampus, NMDA receptor-mediated EPSCs have rapid kinetics and are insensitive to NR2B-selective antagonists. However, expression of NR1 and NR2A subunits alone results in receptors with kinetic properties much faster than those seen at mature synapses (Vicini et al., 1998; Tovar et al., 2000). Experiments with recombinant NMDA receptors expressed in isolated cell systems have shown that coexpression of NR1 subunits with both NR2A and NR2B subunits results in functional receptors that share kinetic and pharmacological properties with those of synaptic NMDA receptors. Whereas some of these properties result from the presence of both NR1/NR2A and NR1/NR2B subunits, it has been suggested that these receptors may also be triheteromeric-containing NR1/NR2A/NR2B subunits (Stocca and Vicini, 1998; Tovar and Westbrook, 1999; Prybylowski et al., 2002). In agreement with this suggestion, biochemical studies have also shown that receptors containing both NR2A and NR2B subunits are present in central neurons (Sheng et al., 1994; Chazot and Stephenson, 1997; Luo et al., 1997). Although one study suggested that these trimeric receptors are not sensitive to NR2B-selective antagonists (Brimecombe et al., 1997), others have concluded that they retain their sensitivity to these antagonists (Kew et al., 1998; Hawkins et al., 1999).

The exact subunit composition of functional NMDA receptors has been much debated. At least two molecules of glutamate and two of glycine are required for NMDA receptor activation (Benveniste and Mayer, 1991; Clements and Westbrook, 1991), so at least four subunits must co-assemble in the functional receptor. However, different studies have suggested that functional receptors could be either pentamers or tetramers containing either two or three NR1 subunits and two or three NR2 subunits (Behe et al., 1995; Premkumar and Auerbach, 1997; Laube et al., 1998; Hawkins et al., 1999; Schorge and Colquhoun, 2003). If NMDA receptors are tetramers containing two NR1 subunits and two NR2 subunits (Behe et al., 1995; Laube et al., 1998; Schorge and Colquhoun, 2003), then our data are consistent with the suggestion that receptors at synapses at CeL neurons contain two NR1 and two NR2B subunits. As discussed previously, the kinetic properties of expressed NR1/NR2A receptors seem to be too rapid to explain the kinetics of the EPSC recorded at synapses in 
either the hippocampus or LA. Thus, receptors at synapses on pyramidal neurons in the LA and those in hippocampal CA1 neurons may contain both NR2A and NR2B subunits. The higher sensitivity of the EPSC to NR2B-selective antagonists at synapses in the LA suggests the additional presence of NR1/NR2Bcontaining receptors at these synapses. However, this possibility is difficult to reconcile with the kinetic similarities between EPSCs in the LA and those recorded from hippocampal CA1 neurons and the fact that the kinetics of the slow component of the EPSC in LA neurons is faster than that for the slow component in CeL neurons and much faster than that measured for NR1/NR2B subunits expressed alone (Vicini et al., 1998). Thus, the exact composition of the synaptic NMDA receptors in LA neurons remains to be elucidated. It is notable that although expressed NMDA receptors that lack NR2B subunits are insensitive to low concentrations of ifenprodil (Williams, 1993; Vicini et al., 1998), NMDA receptors from animals lacking NR2B subunits do show a small block by ifenprodil (Tovar et al., 2000). It is, therefore, conceivable that other factors besides the presence of NR2B subunits may affect the sensitivity of NMDA receptors to these compounds, explaining the difference in sensitivity of the EPSC to ifenprodil and CP-101,606 between hippocampal neurons and those in the LA.

The amygdala is essential for the acquisition and expression of the fear conditioning (LeDoux, 2000; Davis and Whalen, 2001). A converging body of literature over the last 15 years has suggested that activation of NMDA receptors within the basolateral amygdala is essential in the acquisition, and perhaps the maintenance, of fear conditioning (Blair et al., 2001; Walker and Davis, 2002). Recent data have shown that infusion of the selective NR2B antagonist ifenprodil into the amygdala disrupts the acquisition of fear conditioning, and it has been suggested that the site of action of ifenprodil is in the LA (Rodrigues et al., 2001). Our results showing the presence of synapses expressing largely NR2B subunits in the central nucleus suggest that another likely site of action of ifenprodil for this effect is in the CeA. Interestingly, neurons in the CeA have a different embryonic origin from those in the lateral nucleus (Swanson and Petrovich, 1998; Puelles, 2001). Thus, it is seems possible that glutamatergic synapses on neurons with different embryonic origins may have different developmental fates.

\section{References}

Behe P, Stern P, Wyllie DJ, Nassar M, Schoepfer R, Colquhoun D (1995) Determination of NMDA NR1 subunit copy number in recombinant NMDA receptors. Proc R Soc Lond B Biol Sci 262:205-213.

Benveniste M, Mayer ML (1991) Kinetic analysis of antagonist action at $\mathrm{N}$-methyl-D-aspartic acid receptors. Two binding sites each for glutamate and glycine. Biophys J 59:560-573.

Blair HT, Schafe GE, Bauer EP, Rodrigues SM, LeDoux JE (2001) Synaptic plasticity in the lateral amygdala: a cellular hypothesis of fear conditioning. Learn Mem 8:229-242.

Brimecombe JC, Boeckman FA, Aizenman E (1997) Functional consequences of NR2 subunit composition in single recombinant $N$-methyl-Daspartate receptors. Proc Natl Acad Sci USA 94:11019-11024.

Carmignoto G, Vicini S (1992) Activity-dependent decrease in NMDA receptor responses during development of the visual cortex. Science 258:1007-1011.

Cassell MD, Gray TS, Kiss JZ (1986) Neuronal architecture in the rat central nucleus of the amygdala: a cytological, hodological, and immunocytochemical study. J Comp Neurol 246:478-499.

Chavis P, Westbrook G (2001) Integrins mediate functional pre- and postsynaptic maturation at a hippocampal synapse. Nature 411:317-321.

Chazot PL, Stephenson FA (1997) Molecular dissection of native mammalian forebrain NMDA receptors containing the NR1 C2 exon: direct dem- onstration of NMDA receptors comprising NR1, NR2A, and NR2B subunits within the same complex. J Neurochem 69:2138-2144.

Chen N, Luo T, Raymond LA (1999) Subtype-dependence of NMDA receptor channel open probability. J Neurosci 19:6844-6854.

Chenard BL, Menniti FS (1999) Antagonists selective for NMDA receptors containing the NR2B subunit. Curr Pharm Des 5:381-404.

Clements JD, Westbrook GL (1991) Activation kinetics reveal the number of glutamate and glycine binding sites on the $\mathrm{N}$-methyl-D-aspartate receptor. Neuron 7:605-613.

Cull-Candy S, Brickley S, Farrant M (2001) NMDA receptor subunits: diversity, development and disease. Curr Opin Neurobiol 11:327-335.

Davis M, Whalen PJ (2001) The amygdala: vigilance and emotion. Mol Psychiatry 6:13-34.

Dingledine R, Borges K, Bowie D, Traynelis SF (1999) The glutamate receptor ion channels. Pharmacol Rev 51:7-61.

Flint AC, Maisch US, Weishaupt JH, Kriegstein AR, Monyer H (1997) NR2A subunit expression shortens NMDA receptor synaptic currents in developing neocortex. J Neurosci 17:2469-2476.

Hawkins LM, Chazot PL, Stephenson FA (1999) Biochemical evidence for the co-association of three $\mathrm{N}$-methyl-D-aspartate (NMDA) R2 subunits in recombinant NMDA receptors. J Biol Chem 274:27211-27218.

Hestrin S (1992) Developmental regulation of NMDA receptor-mediated synaptic currents at a central synapse. Nature 357:686-689.

Hestrin S, Nicoll RA, Perkel DJ, Sah P (1990) Analysis of excitatory synaptic action in the rat hippocampus using whole cell recording from thin slices. J Physiol (Lond) 422:203-225.

Huettner JE, Bean BP (1988) Block of N-methyl-D-aspartate-activated current by the anticonvulsant MK-801: selective binding to open channels. Proc Natl Acad Sci USA 85:1307-1311.

Kew JN, Richards JG, Mutel V, Kemp JA (1998) Developmental changes in NMDA receptor glycine affinity and ifenprodil sensitivity reveal three distinct populations of NMDA receptors in individual rat cortical neurons. J Neurosci 18:1935-1943.

Kuryatov A, Laube B, Betz H, Kuhse J (1994) Mutational analysis of the glycine-binding site of the NMDA receptor: structural similarity with bacterial amino acid-binding proteins. Neuron 12:1291-1300.

Kutsuwada T, Kashiwabuchi N, Mori H, Sakimura K, Kushiya E, Araki K, Meguro H, Masaki H, Kumanishi T, Arakawa M, Mishina M (1992) Molecular diversity of the NMDA receptor channel. Nature 358:36-41.

Laube B, Kuhse J, Betz H (1998) Evidence for a tetrameric structure of recombinant NMDA receptors. J Neurosci 18:2954-2961.

Laurie DJ, Seeburg PH (1994) Regional and developmental heterogeneity in splicing of the rat brain NMDAR1 mRNA. J Neurosci 14:3180-3194.

LeDoux JE (2000) Emotion circuits in the brain. Annu Rev Neurosci 23:155-184.

Luo J, Wang Y, Yasuda RP, Dunah AW, Wolfe BB (1997) The majority of $\mathrm{N}$-methyl-D-aspartate receptor complexes in adult rat cerebral cortex contain at least three different subunits (NR1/NR2A/NR2B). Mol Pharmacol 51:79-86.

Mahanty NK, Sah P (1999) Excitatory synaptic inputs to pyramidal neurons of the lateral amygdala. Eur J Neurosci 11:1217-1222.

Maren S (2001) Neurobiology of Pavlovian fear conditioning. Annu Rev Neurosci 24:897-931.

McBain CJ, Mayer ML (1994) NMDA receptor structure and fucntion. Physiol Rev 74:723-760.

McKernan MG, Shinnick-Gallagher P (1997) Fear conditioning induces a lasting potentiation of synaptic currents in vitro. Nature 390:607-611.

Miserendino MJD, Sananes CB, Melia KR, Davis M (1990) Blocking of acquisition but not expression of conditioned fear-potentiated startle by NMDA antagonists in the amygdala. Nature 345:716-718.

Monyer H, Burnashev N, Laurie DJ, Sakmann B, Seeburg PH (1994) Developmental and regional expression in the rat brain and functional properties of four NMDA receptors. Neuron 12:529-540.

Nakanishi N, Axel R, Shneider NA (1992) Alternative splicing generates functionally distinct $N$-methyl-D-aspartate receptors. Proc Natl Acad Sci USA 89:8552-8556.

Philpot BD, Sekhar AK, Shouval HZ, Bear MF (2001) Visual experience and deprivation bidirectionally modify the composition and function of NMDA receptors in visual cortex. Neuron 29:157-169.

Premkumar LS, Auerbach A (1997) Stoichiometry of recombinant $\mathrm{N}$-methyl-D-aspartate receptor channels inferred from single-channel current patterns. J Gen Physiol 110:485-502. 
Prybylowski K, Fu Z, Losi G, Hawkins LM, Luo J, Chang K, Wenthold RJ, Vicini S (2002) Relationship between availability of NMDA receptor subunits and their expression at the synapse. J Neurosci 22:8902-8910.

Puelles L (2001) Thoughts on the development, structure and evolution of the mammalian and avian telencephalic pallium. Philos Trans R Soc Lond B Biol Sci 356:1583-1598.

Quirk GJ, Repa C, LeDoux JE (1995) Fear conditioning enhances shortlatency auditory responses of lateral amygdaloid neurons: parallel recordings in the freely behaving rat. Neuron 15:1029-1039.

Rodrigues SM, Schafe GE, LeDoux JE (2001) Intra-amygdala blockade of the NR2B subunit of the NMDA receptor disrupts the acquisition but not the expression of fear conditioning. J Neurosci 21:6889-6896.

Rose-Meyer RB, Mellick AS, Garnham BG, Harrison GJ, Massa HM, Griffiths LR (2003) The measurement of adenosine and estrogen receptor expression in rat brains following ovariectomy using quantitative PCR analysis. Brain Res Brain Res Protoc 11:9-18.

Rosenmund C, Clements JD, Westbrook GL (1993) Nonuniform probability of glutamate release at a hippocampal synapse. Science 262:754-757.

Rumbaugh G, Vicini S (1999) Distinct synaptic and extrasynaptic NMDA receptors in developing cerebellar granule neurons. J Neurosci 19:10603-10610.

Schorge S, Colquhoun D (2003) Studies of NMDA receptor function and stoichiometry with truncated and tandem subunits. J Neurosci 23:1151-1158.

Sheng M, Cummings J, Roldan LA, Jan YN, Jan LY (1994) Changing subunit composition of heteromeric NMDA receptors during development of rat cortex. Nature 368:144-147.

Stocca G, Vicini S (1998) Increased contribution of NR2A subunit to synaptic NMDA receptors in developing rat cortical neurons. J Physiol 507:13-24.
Swanson LW, Petrovich GD (1998) What is the amygdala? Trends Neurosci 21:323-331.

Tovar KR, Westbrook GL (1999) The incorporation of NMDA receptors with a distinct subunit composition at nascent hippocampal synapses in vitro. J Neurosci 19:4180-4188.

Tovar KR, Sprouffske K, Westbrook GL (2000) Fast NMDA receptormediated synaptic currents in neurons from mice lacking the epsilon2 (NR2B) subunit. J Neurophysiol 83:616-620.

Vicini S, Wang JF, Li JH, Zhu WJ, Wang YH, Luo JH, Wolfe BB, Grayson DR (1998) Functional and pharmacological differences between recombinant $N$-methyl-D-aspartate receptors. J Neurophysiol 79:555-566.

Walker DL, Davis M (2002) The role of amygdala glutamate receptors in fear learning, fear-potentiated startle, and extinction. Pharmacol Biochem Behav 71:379-392.

Weisskopf MG, LeDoux JE (1999) Distinct populations of NMDA receptors at subcortical and cortical inputs to principal cells of the lateral amygdala. J Neurophysiol 81:930-934.

Williams K (1993) Ifenprodil discriminates subtypes of the N-methyl-Daspartate receptor: selectivity and mechanisms at recombinant heteromeric receptors. Mol Pharmacol 44:851-859.

Williams K, Russell SL, Shen YM, Molinoff PB (1993) Developmental switch in the expression of NMDA receptors occurs in vivo and in vitro. Neuron 10:267-278.

Yamakura T, Shimoji K (1999) Subunit- and site-specific pharmacology of the NMDA receptor channel. Prog Neurobiol 59:279-298.

Zhong J, Carrozza DP, Williams K, Pritchett DB, Molinoff PB (1995) Expression of mRNAs encoding subunits of the NMDA receptor in developing rat brain. J Neurochem 64:531-539. 